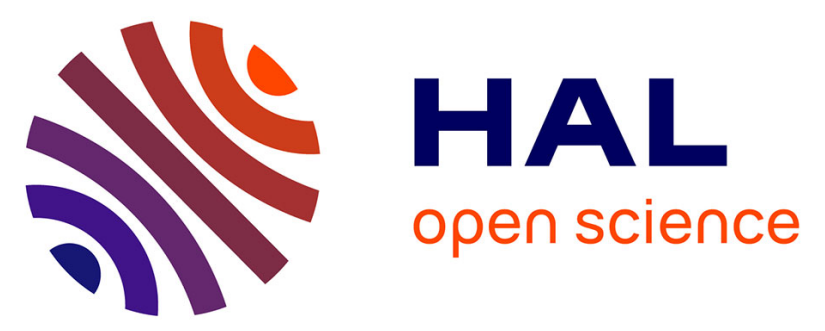

\title{
Assimilation of Odin/SMR O3 and N2O measurements in a three-dimensional chemistry transport model.
}

\author{
L. El Amraoui, P. Ricaud, Jakub Urban, Bertrand Théodore, Alain
}

Hauchecorne, N. Lautie, J. de La Noe, Marielle Guirlet, E. Le Flochmoën, D.

Murtagh, et al.

\section{- To cite this version:}

L. El Amraoui, P. Ricaud, Jakub Urban, Bertrand Théodore, Alain Hauchecorne, et al.. Assimilation of Odin/SMR O3 and N2O measurements in a three-dimensional chemistry transport model.. Journal of Geophysical Research: Atmospheres, 2004, 109 (D22), pp.D22304. 10.1029/2004JD004796 . hal00136450

\section{HAL Id: hal-00136450 \\ https://hal.science/hal-00136450}

Submitted on 4 Dec 2017

HAL is a multi-disciplinary open access archive for the deposit and dissemination of scientific research documents, whether they are published or not. The documents may come from teaching and research institutions in France or abroad, or from public or private research centers.
L'archive ouverte pluridisciplinaire HAL, est destinée au dépôt et à la diffusion de documents scientifiques de niveau recherche, publiés ou non, émanant des établissements d'enseignement et de recherche français ou étrangers, des laboratoires publics ou privés. 


\section{Assimilation of Odin/SMR $\mathrm{O}_{3}$ and $\mathrm{N}_{2} \mathrm{O}$ measurements in a three-dimensional chemistry transport model}

L. El Amraoui, ${ }^{1}$ P. Ricaud, ${ }^{1}$ J. Urban, ${ }^{1}$ B. Théodore ${ }^{2}$ A. Hauchecorne,${ }^{3}$ N. Lautié, ${ }^{4}$ J. De La Noë, ${ }^{1}$ M. Guirlet, ${ }^{2}$ E. Le Flochmoën, ${ }^{1}$ D. Murtagh, ${ }^{4}$ E. Dupuy, ${ }^{1}$ U. Frisk, ${ }^{5}$ and O. F. d'Andon ${ }^{2}$

Received 21 March 2004; revised 26 August 2004; accepted 20 September 2004; published 20 November 2004.

[1] A method for assimilating observations of long-lived species such as ozone $\left(\mathrm{O}_{3}\right)$ and nitrous oxide $\left(\mathrm{N}_{2} \mathrm{O}\right)$ in a three-dimensional chemistry transport model (3D-CTM) is described. The model is forced by the temperature and wind analyses from the European Centre for Medium-Range Weather Forecasts (ECMWF). The $\mathrm{O}_{3}$ and $\mathrm{N}_{2} \mathrm{O}$ fields used in this study are obtained from the Sub-Millimeter Radiometer (SMR) aboard the Odin satellite. The assimilation technique used is the sequential statistical interpolation approach. The parametrization of the error covariance matrix of the model forecast field is described. A sensitivity study of the system parameters is done in terms of the OMF (observation minus forecast) vector also called "innovation" vector and in terms of the $\chi^{2}$ (chi-square) test. The effect of the correlation distances is critical for the assimilated field. The RMS (root mean square) of the OMF for the correlation distances is minimal for values of $1500 \mathrm{~km}$ in the meridional direction and $500 \mathrm{~km}$ in the zonal direction for both $\mathrm{O}_{3}$ and $\mathrm{N}_{2} \mathrm{O}$. The treatment of the meridional distance as a function of latitude does not reveal an important improvement. The $\chi^{2}$ diagnostic shows that the asymptotic value of the model error (the model error of saturation) is optimal for the value of $12.5 \%$ for $\mathrm{O}_{3}$ and $18 \%$ for $\mathrm{N}_{2} \mathrm{O}$. We demonstrate the applicability of the developed assimilation method for the Odin/SMR data. We also present first results of the assimilation of Odin/SMR ozone and nitrous oxide for the period from 22 December 2001 to 17 January

2002. INDEX TERMS: 3337 Meteorology and Atmospheric Dynamics: Numerical modeling and data assimilation; 0340 Atmospheric Composition and Structure: Middle atmosphere - composition and chemistry; 0341 Atmospheric Composition and Structure: Middle atmosphere - constituent transport and chemistry (3334); KEYWORDS: assimilation, chemistry, transport

Citation: El Amraoui, L., et al. (2004), Assimilation of Odin/SMR $\mathrm{O}_{3}$ and $\mathrm{N}_{2} \mathrm{O}$ measurements in a three-dimensional chemistry transport model, J. Geophys. Res., 109, D22304, doi:10.1029/2004JD004796.

\section{Introduction}

[2] Several satellite instruments such as the Total Ozone Mapping Spectrometer (TOMS), the Microwave Limb Sounder (MLS) on the Upper Atmospheric Research Satellite (UARS) and the Global Ozone Monitoring Experiment (GOME) have been launched in the past ten years, in order to make measurements of atmospheric species in the stratosphere and mesosphere. These instruments provided a large data set of ozone and other chemical species and have

\footnotetext{
${ }^{1}$ Observatoire Aquitain des Sciences de l'Univers, L3AB, Floirac, France.

${ }^{2}$ ACRI-ST, Sophia-Antipolis, France.

${ }^{3}$ Service d'Aéronomie du CNRS, Paris, France.

${ }^{4}$ Department of Radio and Space Science, Chalmers University of Technology, Göteborg, Sweden.

${ }^{5}$ Swedish Space Corporation, Solna, Sweden.

Copyright 2004 by the American Geophysical Union. 0148-0227/04/2004JD004796
}

helped scientists to study and to better understand the evolution of the Earth's middle atmosphere. A new generation of satellite instruments aboard the ESA satellite ENVISAT or the EOS-AURA satellite of NASA will provide measurements of many species and will help to improve the observation quality and thus contribute to better understand the complexity of the atmospheric phenomena. The Odin satellite is one of the most recent satellites. It has the original mission to make both astronomy and aeronomy measurements and includes two instruments. A ultra-violetvisible and near Infra-Red instrument, the Optical Spectrograph and Infrared Imager System (OSIRIS), measures ozone $\left(\mathrm{O}_{3}\right)$, nitrogen dioxide $\left(\mathrm{NO}_{2}\right)$ and aerosols. The second instrument is the Sub-Millimeter Radiometer (SMR) capable of detecting simultaneously many species such as $\mathrm{O}_{3}$, chlorine monoxide $(\mathrm{ClO})$ and nitrous oxide $\left(\mathrm{N}_{2} \mathrm{O}\right)$ in the stratosphere.

[3] On the other hand, several kinds of models have also been used to study the Earth's atmosphere and in particular the ozone depletion in the polar regions: trajectory models 
[Pierce and Fairlie, 1993], trajectory-chemistry models [Becker et al., 2000], diabatic trajectory-chemistry model (DTCM) [Lukyanov et al., 2003], and three-dimensional chemical transport models (3D-CTM) [Lefèvre et al., 1994; Chipperfield, 1999].

[4] Data assimilation consists of combining in an optimal way observations provided by instruments with an a priori knowledge about a physical system such as a model output. In atmospheric research this technique has become a powerful tool for improving model results by constraining the a priori knowledge of the model with the observations in order to determine the true state of the atmosphere.

[5] Generally the assimilation methods are divided into two families: the variational method [Fisher and Lary, 1995; Elbern and Schmidt, 1999] and the sequential method [Khattatov et al., 2000; Levelt et al., 1998]. The difference between both methods is not the subject of this paper. A detailed discussion of the two methods and their limitations is presented by Khattatov et al. [1999] and by Chipperfield et al. [2002].

[6] The aim of this work is (1) to determine the optimal parameters of the assimilation system when applied to $\mathrm{O}_{3}$ and $\mathrm{N}_{2} \mathrm{O}$ fields measured by the Odin/SMR instrument and (2) to present first results of the assimilation system. The parameters concerned by this study are the correlation distances of the forecast error covariance matrix and the model error.

[7] Data from Odin/SMR are presented in section 2. The assimilation technique and the assimilation parameters are described in section 3. Section 4 deals with the optimization of important parameters: the model error and the correlation distances. Results of the assimilation runs for $\mathrm{O}_{3}$ and $\mathrm{N}_{2} \mathrm{O}$ are presented and discussed in section 5 .

\section{Odin/SMR Data}

[8] Odin is a Swedish-led mini-satellite funded by Sweden, France, Canada and Finland [Murtagh et al., 2002]. It was launched in February 2001 into a polar Sunsynchronous circular orbit with the ascending node at 18 hours and an inclination of about $97.8^{\circ}$. The altitude of the satellite is $\sim 600 \mathrm{~km}$ and the duration of one orbit is 96 minutes. The satellite makes about 15 orbits per day and provides a global coverage in the sense that all longitudinal ranges have been sampled. Measurements are normally made in the plane of the orbit covering the latitude range from $83^{\circ} \mathrm{S}$ to $83^{\circ} \mathrm{N}$. Each orbit contains about $60 \mathrm{limb}$ scans profiles of each measured species. The aeronomy part is devoted to the study of chemical and dynamical processes in the stratosphere and mesosphere. The SMR instrument aboard the Odin satellite consists of 4 submillimeter radiometers in the range 486-504, 541-558, 547-564 and 563-580 GHz. SMR performs passive atmospheric observations in the stratosphere and mesosphere by using the limb-sounding technique. The detected signals are spectrally analyzed with a resolution of $2 \mathrm{MHz}$ by two auto-correlator spectrometers of $800 \mathrm{MHz}$ bandwidth each.

[9] For the aeronomy part of the Odin mission there are four observation modes: the stratospheric, the oddhydrogen, the odd-nitrogen, and the water isotope mode. The stratospheric mode provides measurements of major stratospheric constituents such as $\mathrm{O}_{3}, \mathrm{ClO}, \mathrm{N}_{2} \mathrm{O}$ and $\mathrm{HNO}_{3}$.
[10] The vertical profiles of these species are simultaneously retrieved using the MOLIERE-5 code (Microwave Observation Line Estimation and Retrieval, version 5) [Urban et al., 2004] which is installed within the French level 2 processor CTSO (Chaîne de Traitement Scientifique Odin) [Baron, 1999; Lautié, 2003]. The retrieval technique used is the Optimal Estimation Method [Rodgers, 2000].

[11] In the stratospheric mode, the Odin/SMR instrument scans the limb of the atmosphere from 7 to $70 \mathrm{~km}$ in about 90 seconds. Throughout this work we use CTSO-version 222 data. The vertical resolution of the measurements in the stratosphere is of about $2 \mathrm{~km}$. Both $\mathrm{N}_{2} \mathrm{O}$ and $\mathrm{O}_{3}$ are retrieved in the $501.8 \mathrm{GHz}$ band. Typically $\mathrm{N}_{2} \mathrm{O}$ is retrieved in the stratosphere above $15 \mathrm{~km}$ with a single-scan precision in the order of $5 \%$, and $\mathrm{O}_{3}$ between $\sim 20$ and $\sim 50 \mathrm{~km}$ with a single-scan precision of about $25 \%$. The preliminary validation analysis of the Odin/SMR instrument indicates that the upper limits of systematic errors of the measurements in the lower stratosphere is about $20-40$ ppbv for $\mathrm{N}_{2} \mathrm{O}$, and 1 ppmv for $\mathrm{O}_{3}$ in the $501.8 \mathrm{GHz}$ band.

\section{Data Assimilation Tool}

\subsection{MSDOL System}

[12] The MSDOL system (Monitoring of Stratospheric Depletion of the Ozone Layer) has been developed in the framework of the preparation of the exploitation of ENVISAT data with the aim to assimilate vertical profiles of stratospheric ozone measured by satellite experiments [Hauchecorne et al., 1999]. The system assimilates in a optimal way satellite measurements that are irregularly located in space and time using the sequential assimilation technique. The model is a 3D-CTM of the middle atmosphere driven by external wind and temperature fields. In the next subsections, we give the description of both the model and the assimilation module used in the MSDOL system.

\subsection{Model}

[13] The atmospheric model used for this study is a version of the ROSE (Research for Ozone in the Stratosphere and its Evolution) model. We only give a brief description of this model. For a complete description, the reader is referred to Rose and Brasseur [1989]. The used version is driven by ECMWF wind and temperature fields. It provides the distribution of 38 chemical species (27 longlived and 11 short-lived species) through 145 chemical or photolysis reactions, including heterogeneous processes, within 5 chemical families. The altitude is defined at constant pressure for 36 pressure levels between 250 and $0.1 \mathrm{hPa}$ (from $\sim 10$ to $\sim 60 \mathrm{~km}$ ) which gives a vertical resolution of $\sim 1.3 \mathrm{~km}$. The model horizontal resolution is $2.5^{\circ}$ both in latitude and longitude and the transport scheme is semi-Lagrangian. The model can be run with a time-step of 30 minutes with or without the chemical processes.

\subsection{Assimilation Module}

[14] In this section we give a brief description of the mathematical approach of the assimilation scheme based on the equations of the Kalman filter. The Kalman filter has been successfully applied to the assimilation of tracer measurements [Levelt et al., 1998; Khattatov et al., 2000]. The sequential assimilation algorithm used in this work uses the Optimal Interpolation (OI) technique, an approximation 
of the Kalman filter designed to assimilate measurements of long-lived stratospheric chemical species such as $\mathrm{O}_{3}$ and $\mathrm{N}_{2} \mathrm{O}$. The assimilation of short-lived photochemical species in such a kind of assimilation system is meaningless because the model window is very large compared to the lifetime of the species.

[15] In the OI method, the concentration state of the species is expressed as a linear combination of the background state vector $\mathbf{x}_{\mathbf{b}}$ and the vector of observations $\mathbf{y}$ :

$$
\begin{gathered}
\mathbf{x}_{\mathbf{a}}=\mathbf{x}_{\mathbf{b}}+\mathbf{K}\left(\mathbf{y}-\mathbf{H}\left(\mathbf{x}_{\mathbf{b}}\right)\right) \\
\mathbf{K}=\mathbf{B} \mathbf{H}^{\mathbf{T}}\left(\mathbf{H B H} \mathbf{H}^{\mathbf{T}}+\mathbf{R}\right)^{-\mathbf{1}}
\end{gathered}
$$

where $\mathbf{x}_{\mathbf{a}}$ is the analysis state and $\mathbf{K}$ is the weighting function matrix which is a function of the forecast error covariance matrix $\mathbf{B}$, of the observation error covariance matrix $\mathbf{R}$ and of the interpolation operator $\mathbf{H}$ mapping the 3D model field on the observation locations by linear interpolation. The observations are assumed to be uncorrelated, i.e., the $\mathbf{R}$ matrix is diagonal. Their elements (variances) $\mathbf{r}_{\mathbf{i i}}$ are computed from the uncertainties of the SMR data

$$
\mathbf{r}_{\mathrm{ii}}=\sigma_{\mathrm{ii}}^{2}
$$

where $\sigma_{\text {ii }}$ is the total error of the measurements.

[16] The error covariance matrix of the analysis is expressed as [Lorenc, 1986]:

$$
\mathbf{A}=\mathbf{B}-\mathbf{K H B}
$$

[17] In our case the $\mathbf{B}$ matrix is expressed as

$$
\mathbf{B}=\mathbf{D}^{1 / 2} \mathbf{C D}^{1 / 2}
$$

where $\mathbf{C}$ is the matrix containing the correlations and $\mathbf{D}$ the matrix containing the variances of the analyzed species. (The 1/2 sign means the square root of the variances). The time evolution of the forecast error variances is expressed as

$$
\mathbf{b}_{\mathrm{ii}}(\mathbf{t}+\triangle \mathbf{t})=\mathbf{M}\left(\mathbf{b}_{\mathrm{ii}}(\mathbf{t})\right)+\mathbf{q}_{\mathrm{ii}}(\mathbf{t})
$$

where $\mathbf{M}$ is the model operator, $\Delta \mathbf{t}$ the integration time of the model (fixed to 30 minutes) and $\mathbf{q}_{\mathrm{ii}}(\mathbf{t})$ the error representing the imperfections of the model (the so-called model error). The off-diagonal elements of $\mathbf{B}$ are expressed as

$$
b_{\mathrm{ij}}=c_{\mathrm{ij}}\left(b_{\mathrm{ii}} b_{\mathrm{jj}}\right)^{1 / 2}
$$

where $\mathbf{c}_{\mathbf{i j}}$ is the correlation function of the forecast error which depends only on the distance:

$$
\mathbf{c}_{\mathrm{ij}}=\exp \left(-\left(\frac{\left(\mathbf{d}_{\mathrm{z}}\right)_{\mathrm{ij}}}{2 \mathbf{L}_{\mathrm{z}}}\right)^{2}-\left(\frac{\left(\mathbf{d}_{\mathrm{m}}\right)_{\mathrm{ij}}}{2 \mathbf{L}_{\mathrm{m}}}\right)^{2}\right)
$$

$\left(\mathbf{d}_{\mathbf{z}}\right)_{\mathbf{i j}}$ and $\left(\mathbf{d}_{\mathbf{m}}\right)_{\mathbf{i j}}$ are the zonal and meridional distances between locations $\mathbf{i}$ and $\mathbf{j}$, respectively, and $\mathbf{L}_{\mathbf{z}}$ and $\mathbf{L}_{\mathbf{m}}$ are the zonal and meridional correlations lengths, respectively.
Table 1. RMS of the OMFs for Different Correlations Distance Values

\begin{tabular}{lccc}
\hline \multicolumn{2}{c}{ Correlation Distances } & & \\
\hline Zonal & Meridional & $\mathrm{O}_{3}, \mathrm{ppmv}$ & $\mathrm{N}_{2} \mathrm{O}, \mathrm{ppbv}$ \\
\hline 500 & 200 & 0.844 & 22.813 \\
500 & 500 & 0.835 & 22.392 \\
1000 & 200 & 1.371 & 21.977 \\
1000 & 500 & 0.823 & 21.890 \\
1000 & 1000 & 0.874 & 25.205 \\
1500 & 200 & 0.894 & 21.763 \\
1500 & 500 & 0.817 & 21.314 \\
1500 & 1000 & 0.819 & 21.458 \\
1500 & 1500 & 0.822 & 21.525 \\
\hline
\end{tabular}

The vertical correlation length has a constant value (about 200 meters) whatever the values of $\mathbf{L}_{\mathbf{z}}$ and $\mathbf{L}_{\mathbf{m}}$ are.

[18] The assimilation algorithm depends on many parameters which should be fixed beforehand. No analytical method exists to choose these parameters and an empirical approach is needed to optimize them.

[19] Many methods have been applied to choose the adjustable parameters: the $\chi^{2}$ (chi-square) diagnostics which should ideally produce values near 1 and should not exhibit a temporal trend [Menard and Chang, 2000; Khattatov et al., 2000] and the minimization of the RMS (Root Mean Square) of the OMF (Observation minus Forecast vector) [Khattatov et al., 2000; Chipperfield et al., 2002; Fierli et al., 2002].

\section{Adjustment of the Assimilation Parameters}

[20] The analysis quality mainly depends on the values of the system parameters. The concerned parameters for the adjustment are: the zonal and the meridional correlation distances $\left(\mathbf{L}_{\mathbf{z}}\right.$ and $\left.\mathbf{L}_{\mathbf{m}}\right)$ and the model error $(q)$.

[21] Khattatov et al. [2000] and Fierli et al. [2002] reveal that the value of $\chi^{2}$ primarily depends on the value of the error growth and not on the correlation distances. On the other hand, the same authors found that the RMS of the OMFs is principally sensitive to the correlation lengths. We adopt the same methodology to tune the assimilation parameters.

\subsection{Correlation Distances}

[22] The adjustment of the correlation lengths is thus done by the minimization of the RMS of the OMFs. The criterium of this test consists of having values of the OMFs as close to zero as possible. In this work, the sequential assimilation scheme is first applied to the Odin/SMR measurements in order to adjust the parameters. Results indicate that the RMS value of the OMFs depends both on the correlation distances and on the model error for both $\mathrm{O}_{3}$ and $\mathrm{N}_{2} \mathrm{O}$ data. The values of the correlation distances have been varied from 200 to $1500 \mathrm{~km}$ for the meridional distance, and from 500 to $1500 \mathrm{~km}$ for the zonal distance. The model error has been varied from $1 \%$ to $45 \%$.

[23] Table 1 reports the root mean square values of the OMFs for both $\mathrm{O}_{3}$ and $\mathrm{N}_{2} \mathrm{O}$ for all chosen correlation distances. The RMS minimum value of the OMFs for both $\mathrm{O}_{3}$ and $\mathrm{N}_{2} \mathrm{O}$ is obtained for correlation distance values of $1500 \mathrm{~km}$ and $500 \mathrm{~km}$ in zonal and meridional directions, respectively. Khattatov et al. [2000] obtain $1000 \mathrm{~km}$ both in 
zonal and meridional directions when they assimilate MLS data in the 3D-CTM. On the other hand, Fierli et al. [2002] have obtained $500 \mathrm{~km}$ in the zonal direction for the same data but with a high horizontal resolution isentropic model. This shows that the correlation distances of the error covariance matrix depend on the used model rather than on the measurements. The dependence of the meridional distance as a function of latitude was also investigated; the result does not reveal any important improvement in comparison with a constant value of $\mathbf{L}_{\mathbf{m}}$.

\subsection{Model Error}

[24] The model error variance (equation (5)) describes the increase of the forecast error variance due to model imperfections. In the MSDOL system the variation of the model error with time is assumed to be [Savijärvi, 1995]

$$
\frac{d q(t)}{d t}=(\alpha+\beta q(t))\left(1-\frac{q(t)}{q_{s a t}}\right)
$$

where $\alpha$ is the linear growth rate of the error $\left[p p m v s^{-1}\right.$ ], $\beta$ the exponential growth rate $\left[\mathrm{s}^{-1}\right]$ of the error and $q_{\text {sat }}$ is the saturation error.

[25] Stratospheric mode observations are typically done on one day out of three time-shared with other (astronomical) observation modes. Because of this discontinuity in the stream of measurements to be assimilated, we have adjusted the parameters $\alpha$ and $\beta$ in an optimal way in order to assure that the model error does not grow too rapidly and, consequently, the system keeps in mind the information from the previous assimilated observations during periods without measurements.

[26] In Figure 1 we give an example of the evolution of the model error for both ozone and nitrous oxide species.
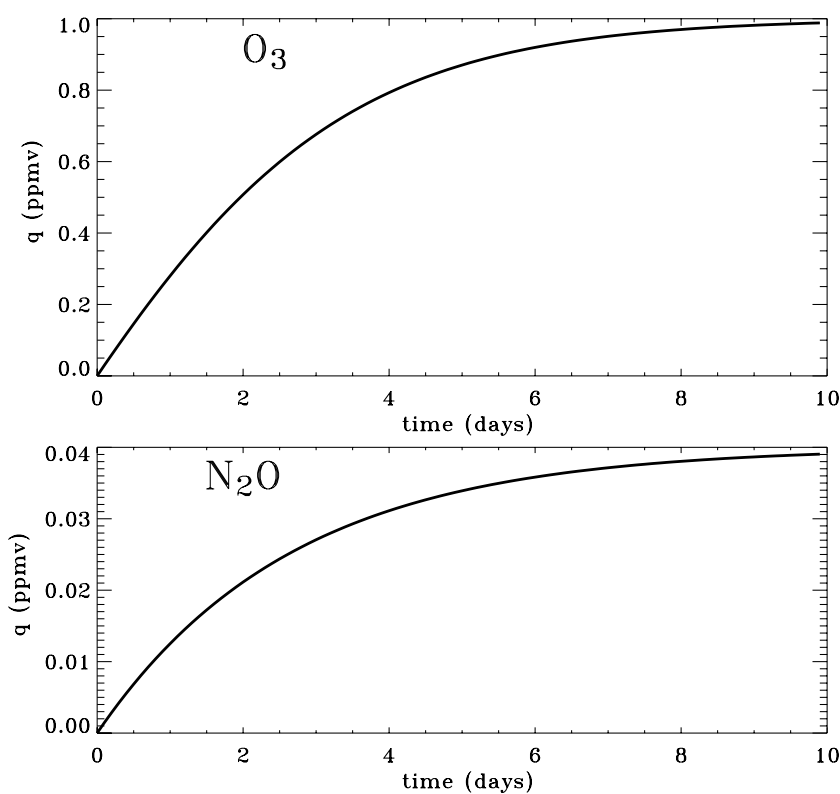

Figure 1. Example of the temporal evolution of the model error for (top) ozone and (bottom) nitrous oxide. The parameters are for ozone and nitrous oxide, respectively: $\alpha=3.472 \cdot 10^{-6}$ and $0.174 \cdot 10^{-6} \mathrm{ppmv} \cdot \mathrm{s}^{-1}, \beta=2.315$. $10^{-6}$ and $0.927 \cdot 10^{-6} \mathrm{~s}^{-1}, q_{\text {sat }}=1$ and $0.04 \mathrm{ppmv}$.
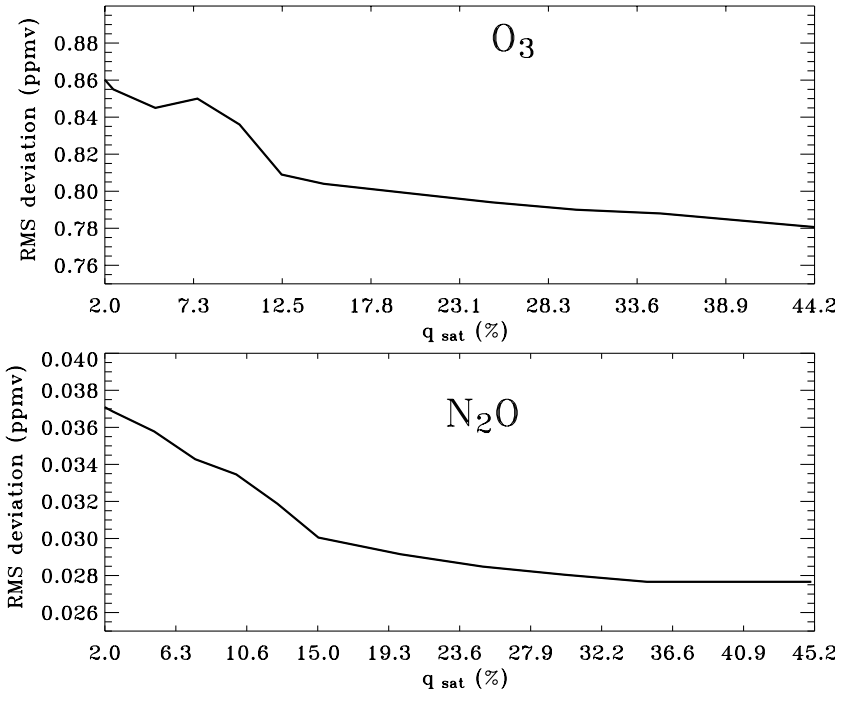

Figure 2. Evolution of the RMS deviation of the OMF for different saturation model error values. Results are shown for (top) ozone and (bottom) nitrous oxide.

The chosen parameters for ozone and nitrous oxide are respectively $3.472 \cdot 10^{-6}$ and $0.174 \cdot 10^{-6} \mathrm{ppmv} \cdot \mathrm{s}^{-1}$ for $\alpha, 2.315 \cdot 10^{-6}$ and $0.927 \cdot 10^{-6} \mathrm{~s}^{-1}$ for $\beta$ and 1 and 0.04 ppmv for $q_{\text {sat }}$. These curves represent the solutions of equation (8).

[27] Using these values of $\alpha$ and $\beta$, we carried out a test in order to investigate the effect of the lack of measurements on the assimilated field. We first run the assimilation system for a given period and obtained a reference output corresponding to a precise date. We then made the same test, but with the last 12 hours of measurements eliminated. The maximal difference between the resulting assimilated field and the reference field on the reference date was $6 \%$. When the last 3 days of measurements were omitted, the maximal difference reaches $18 \%$, which should be still acceptable.

[28] The value of the saturation error $q_{\text {sat }}$ (equation (8)) represents the asymptotic error toward which the analysis error will tend to converge in the absence of measurements. The value of this parameter shown in Figure 1 is just an example. In the MSDOL system, the value of $q_{\text {sat }}$ is proportional to the background field. The proportionality factor is an adjusted parameter that will be extracted from the OMF statistics and the $\chi^{2}$ test.

[29] In a first time we study the behavior of the RMS deviation of the OMFs with respect to the model error. The saturation error $q_{\text {sat }}$ was then varied from 0.1 to $45 \%$ of the background field separately for both ozone and nitrous oxide. In Figure 2 we present the variation of the RMS deviation for different values of the saturation model error. The RMS variation for ozone and nitrous oxide is large for small values of the saturation model error until a value where the variation becomes very small. This value corresponds to about $12.5 \%$ for ozone and $15 \%$ for nitrous oxide. This means that the assimilation system is sensitive to the model error when we assimilate ozone and nitrous oxide starting from the respective values of $12.5 \%$ and $15 \%$. To fix the exact values of the model error which better estimate the matrices of covariances for both ozone and nitrous oxide, we use the $\chi^{2}$ diagnostic. 
Table 2. Mean Value of $\chi^{2} / N$ for Different Values of the Model Error

\begin{tabular}{lcc}
\hline Model Error, \% & $\mathrm{O}_{3}$ & $\mathrm{~N}_{2} \mathrm{O}$ \\
\hline 2.5 & 1.347 & 1.424 \\
5 & 1.304 & 1.361 \\
10 & 1.309 & 1.352 \\
12.5 & 1.108 & 1.156 \\
15 & 0.984 & 1.118 \\
20 & 0.975 & 0.978 \\
25 & 0.956 & 0.942 \\
\hline
\end{tabular}

[30] For each assimilation analysis the value of $\chi^{2}$ is computed as

$$
\chi^{2}=\left(\mathbf{y}-\mathbf{H}\left(\mathbf{x}_{\mathbf{b}}\right)\right)^{\mathbf{T}}\left(\mathbf{H B H} \mathbf{H}^{\mathrm{T}}+\mathbf{R}\right)^{-1}\left(\mathbf{y}-\mathbf{H}\left(\mathbf{x}_{\mathbf{b}}\right)\right)
$$

The saturation error $q_{\text {sat }}$ for this test was varied from 0.2 to $25 \%$ for both ozone and nitrous oxide. As mentioned by Khattatov et al. [2000] and by Chipperfield et al. [2002], the $\chi^{2}$ diagnostic allows to examine the consistency of the error covariance parametrization.

[31] In Table 2 we give the mean value of the quantity $\chi^{2} / N$ for both $\mathrm{O}_{3}$ and $\mathrm{N}_{2} \mathrm{O}$, where $N$ is the number of observations used in the analysis. The mean value of $\chi^{2} / N$ is larger than 1 for small values of the model error which means that the covariances are underestimated. The mean value of $\chi^{2} / N$ is close to 1 for the value of $q_{\text {sat }}$ of $12.5 \%$ for ozone, and is between $15 \%$ and $20 \%$ for nitrous oxide. These results are consistent with the results obtained with the OMF test. For nitrous oxide we have chosen the value of $18 \%$, this model error value gives a mean value of $\chi^{2} / N$ of about 0.997 . The initial value of the analysis error is fixed to be $q_{\text {sat }}$ in the beginning of the assimilation.

[32] To demonstrate the effect of the asymptotic value of the model error in the assimilated field, we show in Figure 3 the results of the zonally averaged time evolution of the ozone analysis (top) and the ozone analysis error (bottom). This presentation is done for two values of the saturation model error: $2.5 \%$ (left) and $12.5 \%$ (right). In the first case,
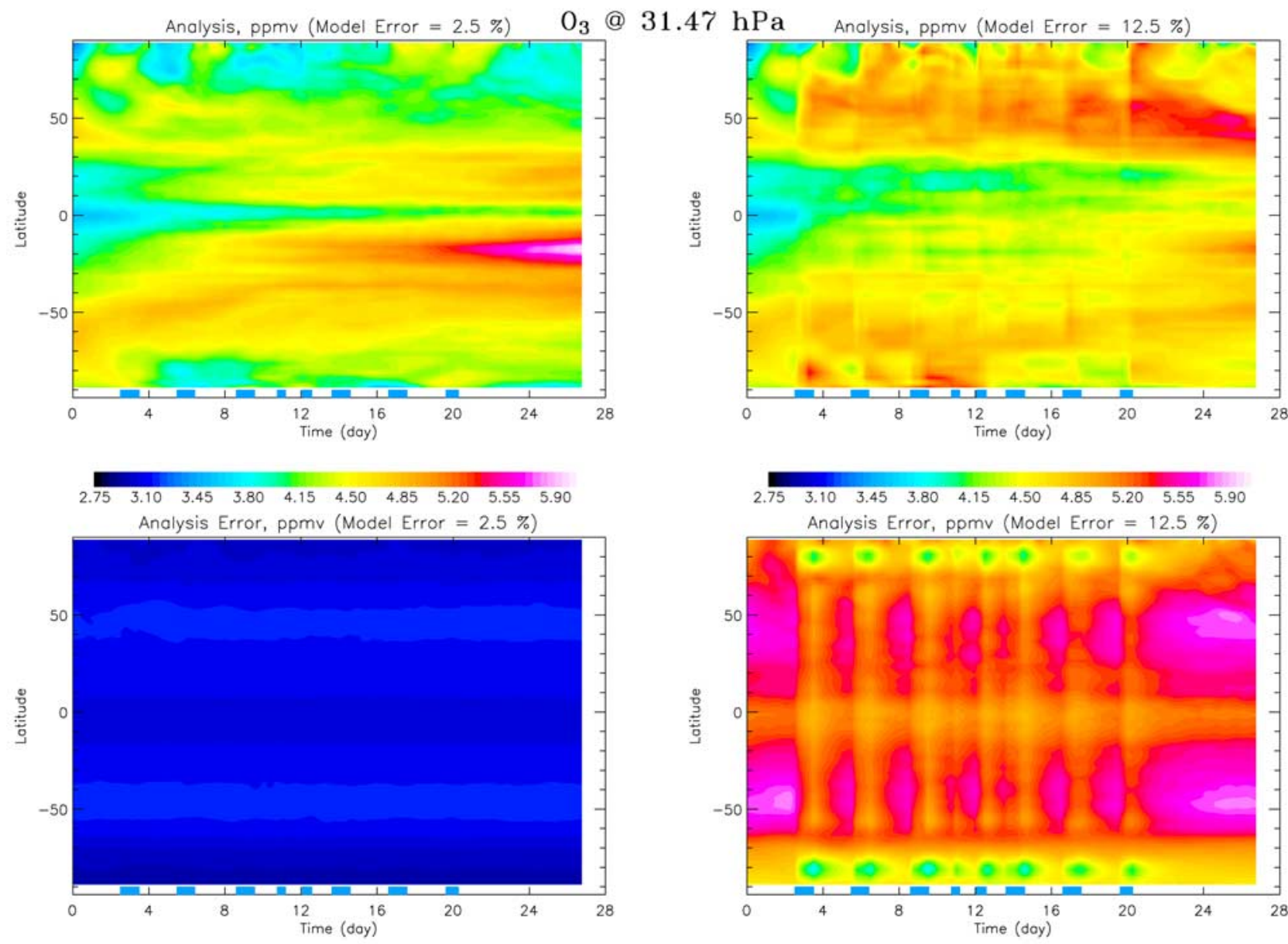

$\begin{array}{llllllllll}0.05 & 0.11 & 0.17 & 0.23 & 0.29 & 0.35 & 0.41 & 0.47 & 0.53 & 0.59\end{array}$

$\begin{array}{llllllllll}0.05 & 0.11 & 0.17 & 0.23 & 0.29 & 0.35 & 0.41 & 0.47 & 0.53 & 0.59\end{array}$

Figure 3. Zonally averaged time evolution of the assimilated ozone field (top frames) and analysis error (bottom frames) at $31.47 \mathrm{hPa}(\sim 24.3 \mathrm{~km})$. The assimilation period is from December 22, 2001, until January 17,2002 . The presentations are done for two values of the saturation model errors: $2.5 \%$ (left frames) and $12.5 \%$ (right frames). 

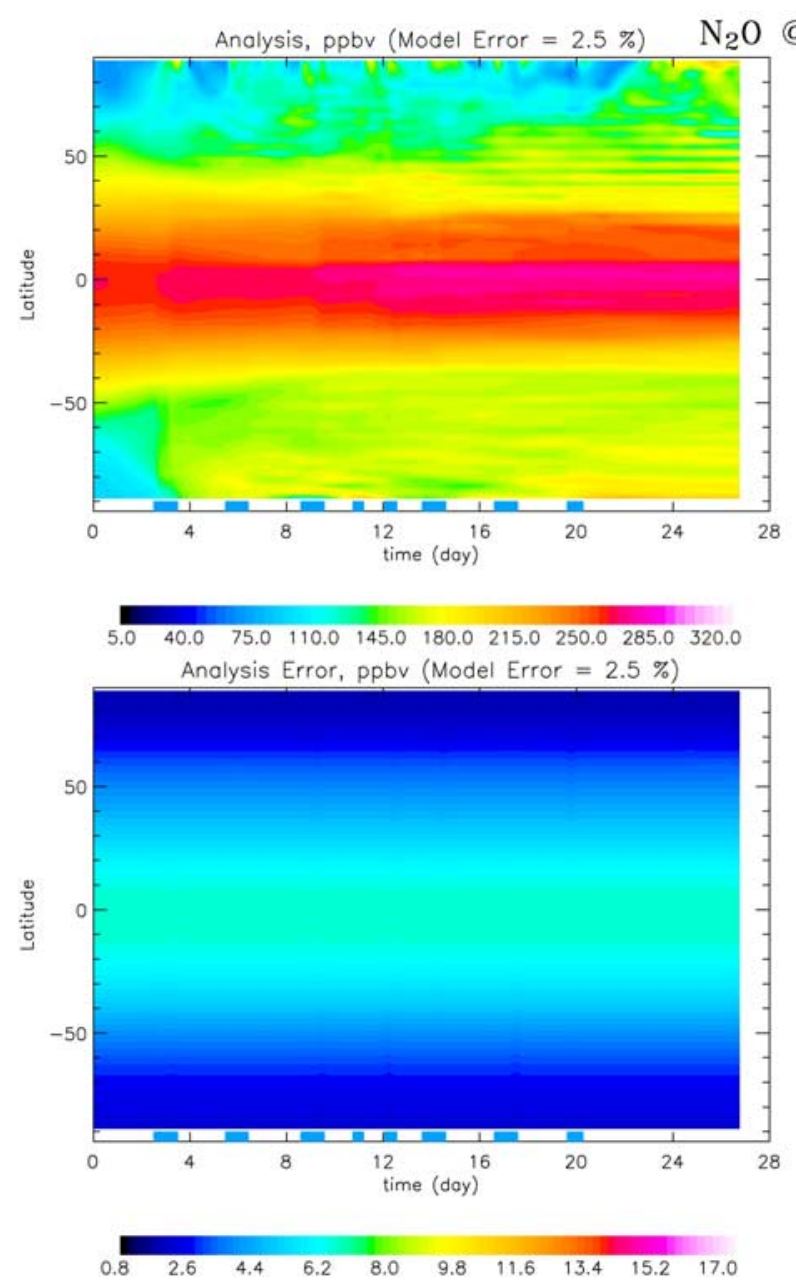
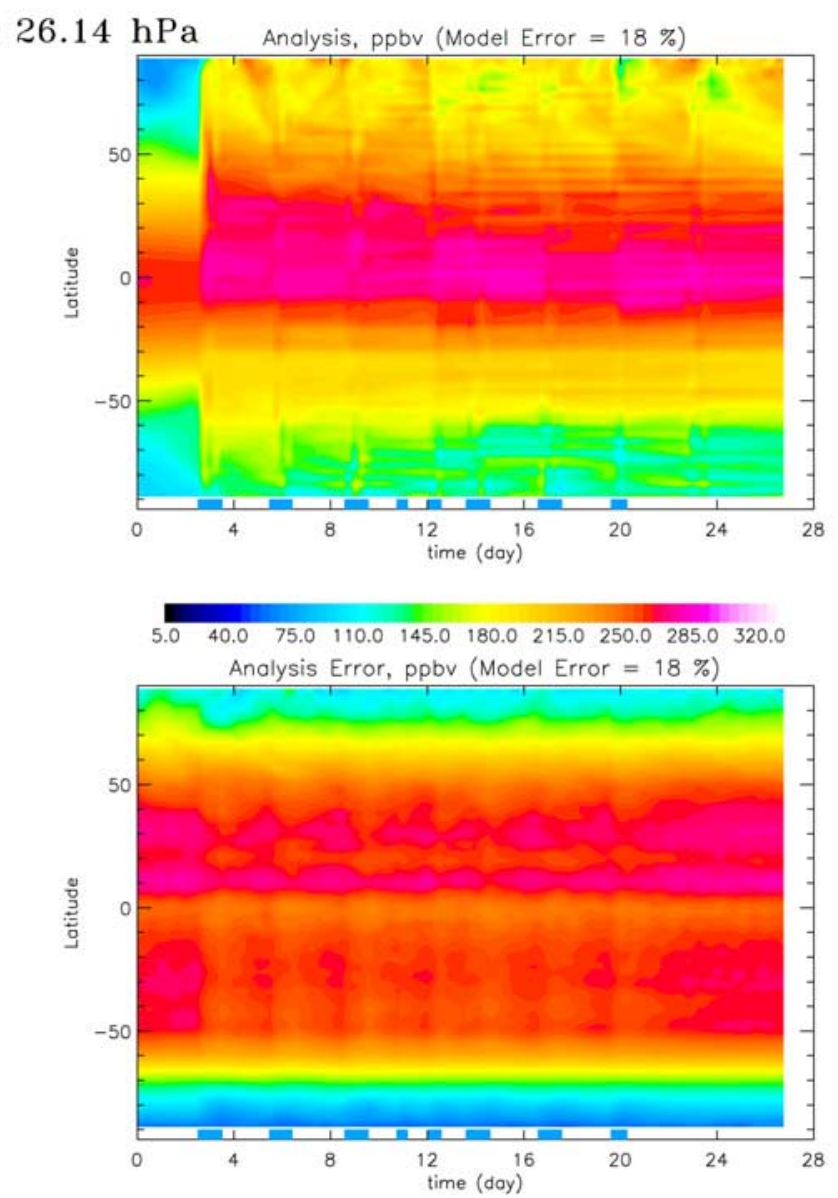

$\begin{array}{llllllllll}14.8 & 16.8 & 18.8 & 20.8 & 22.8 & 24.8 & 26.8 & 28.8 & 30.8 & 32.8\end{array}$

Figure 4. Same as Figure 5, but for nitrous oxide at $26.14 \mathrm{hPa}(\sim 25.6 \mathrm{~km})$. The saturation model errors are: $2.5 \%$ (left frames) and 18\% (right frames).

we clearly show that when measurements are taken into account the analysis error does not change and remains practically constant for the whole assimilation period. Periods when measurements become available are represented by a blue rectangle above the $\mathrm{X}$-axis. In the second case a saturation model error of $12.5 \%$ is assumed. The analysis state shows some differences compared to the first case. In particular, the ozone concentration at midlatitudes is increased due to the assimilation of measurements. Furthermore we notice that both the analysis state and the analysis error strongly depend on the presence of measurements. In the first case $(2.5 \%)$, the analysis state and the analysis error are both insensitive to the presence of measurements. In the second case with $12.5 \%$ of the model error, the analysis state changes when measurements become available. With regard to the analysis error, its initial value at the beginning of the assimilation is the asymptotic value; after meeting the first measurements, the analysis error decreases significantly. However, when there are no measurements, the model error asymptotically increases toward $q_{\text {sat }}$ according to equation (8) as shown in Figure 1.

[33] In Figure 4 we present the same variations for nitrous oxide for model errors of 2.5 and $18 \%$. The same comments as for ozone can be made. For the first value of the saturation model error (i.e., 2.5\%), the analysis field of nitrous oxide is smooth and the analysis error is uniform. When the saturation error increases $(18 \%)$, the assimilated field is much less smooth: it is sensitive to the presence of measurements: measurements modify both the structure and the value of nitrous oxide concentrations. The value of the analysis error also depends on the presence of measurements. Therefore, when measurements become available, the analysis error decreases, and when there are no measurements it tends to increase.

\section{Assimilation Results}

[34] After having fixed the parameters (correlation distances: $1500 \mathrm{~km}$ and $500 \mathrm{~km}$ for zonal and meridional directions respectively for both $\mathrm{O}_{3}$ and $\mathrm{N}_{2} \mathrm{O}$ and $q_{\text {sat }}=$ $12.5 \%$ and $18 \%$ for $\mathrm{O}_{3}$ and $\mathrm{N}_{2} \mathrm{O}$, respectively), assimilation runs were performed separately for ozone and nitrous oxide. The SMR version 222 retrievals are made at constant altitude with a vertical resolution of about $2 \mathrm{~km}$. On the other hand, the assimilation fields (analysis and error fields) and the model outputs are given at constant pressure levels with a vertical resolution of about $1.3 \mathrm{~km}$. In order to have the same level of presentation, SMR 


\section{$\mathrm{O}_{3}$ results $(\mathrm{ppmv}) @ p=26.14 \mathrm{hPa}(z \sim 25.60 \mathrm{~km})$ Assimilation : ( 22/12/2001 - 17/01/2002)}
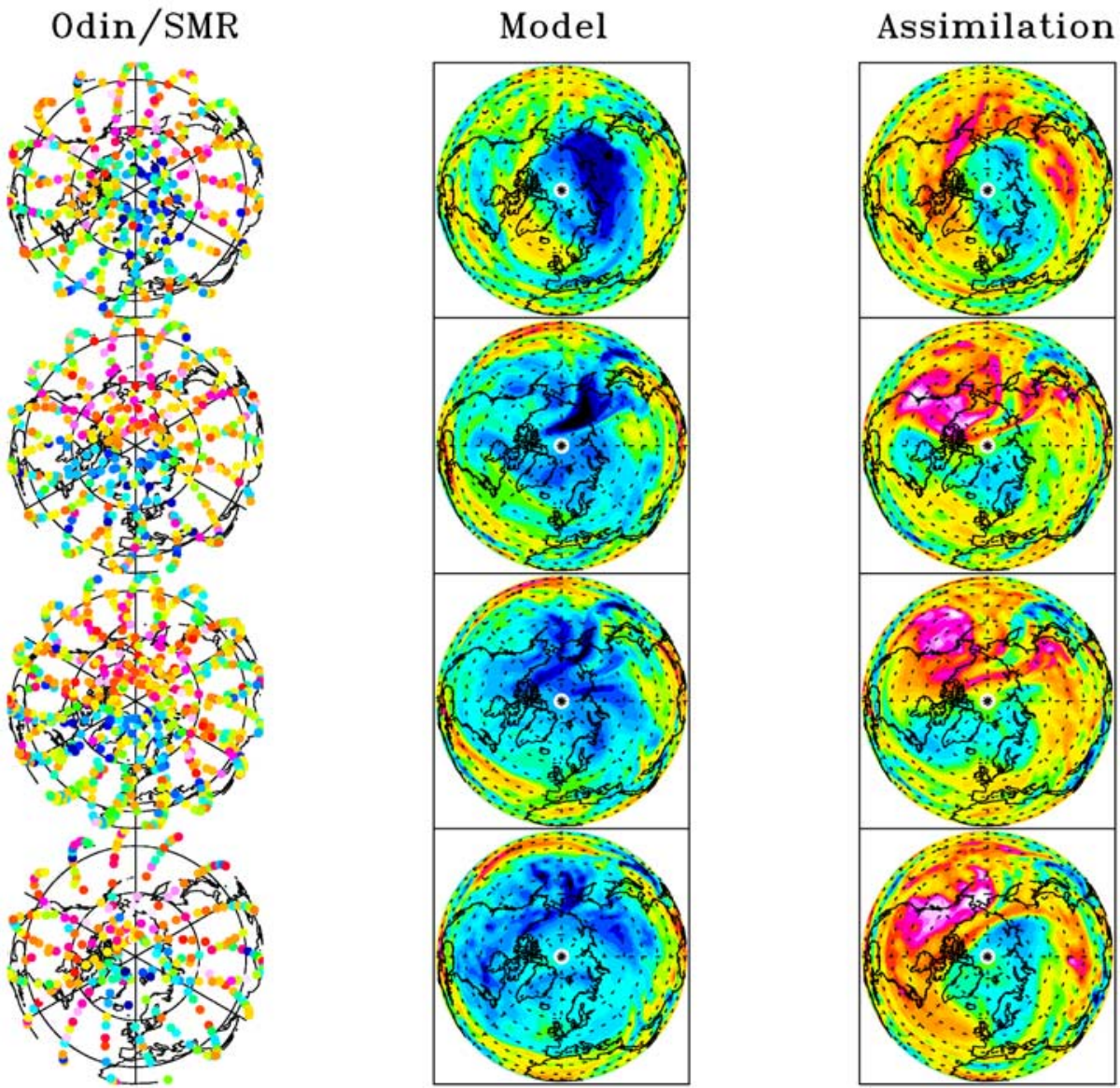

(a)

(b)

(c)

(d)

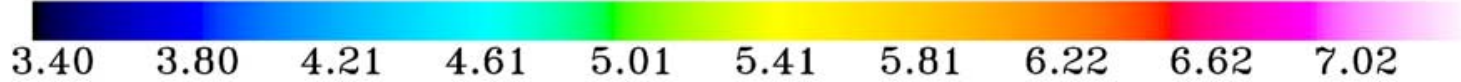

Figure 5. Results of ozone measurements from the SMR instrument in the northern hemisphere and assimilation run made from December 22, 2001, until January 17, 2002. The SMR retrievals are made at constant altitude with a vertical resolution of about $2 \mathrm{~km}$ from $18 \mathrm{~km}$ up to $50 \mathrm{~km}$. The assimilation outputs are given at constant pressure levels with a vertical resolution of about $1.3 \mathrm{~km}$ from 10 up to $60 \mathrm{~km}$. The model output (middle) and the assimilation field (right-hand side) are given at $26.14 \mathrm{hPa}$; the presented SMR measurements (left-hand side) are interpolated on $26.14 \mathrm{hPa}$. (a) SMR measurements are those of 24 hours accumulated from December 24 (12h00) to December 25 (12h00), 2001; model and assimilation fields are those of December 25, 2001, at 12h00 UTC. (b) SMR (from December 30 at $12 \mathrm{~h} 00$ to December 31, 2001, at 12h00); model and assimilation outputs are those of December 31, 2001, at $12 \mathrm{~h} 00$ UTC. (c) SMR (from January 2 at $12 \mathrm{~h} 00$ to January 3, 2002, at 12h00); model and assimilation outputs are those of January 3, 2002, at $12 \mathrm{~h} 00 \mathrm{UTC}$ ). (d) SMR (from January 7 at $12 \mathrm{~h} 00$ to January 8, 2002, at 12h00); model and assimilation outputs are those of January 8, 2002, at 12h00 UTC).

measurements were linearly interpolated on the grid of the assimilated products.

[35] In Figure 5 we show the Odin/SMR ozone measurements (left), the model output without assimilation (middle), and the assimilated ozone field (right) at the $26.14 \mathrm{hPa}$ pressure level $(\sim 25.6 \mathrm{~km})$. The Odin/SMR measurements presented for different periods correspond to measurements taken during 24 hours before the indicated date of the assimilation outputs. The ozone mixing ratios are quite underestimated by the model and the corresponding minima 


\section{$\mathrm{N}_{2} \mathrm{O}$ results (ppbv) @ $p=45.63 \mathrm{hPa}(z \sim 21.70 \mathrm{~km})$ Assimilation : ( $22 / 12 / 2001-17 / 01 / 2002)$}
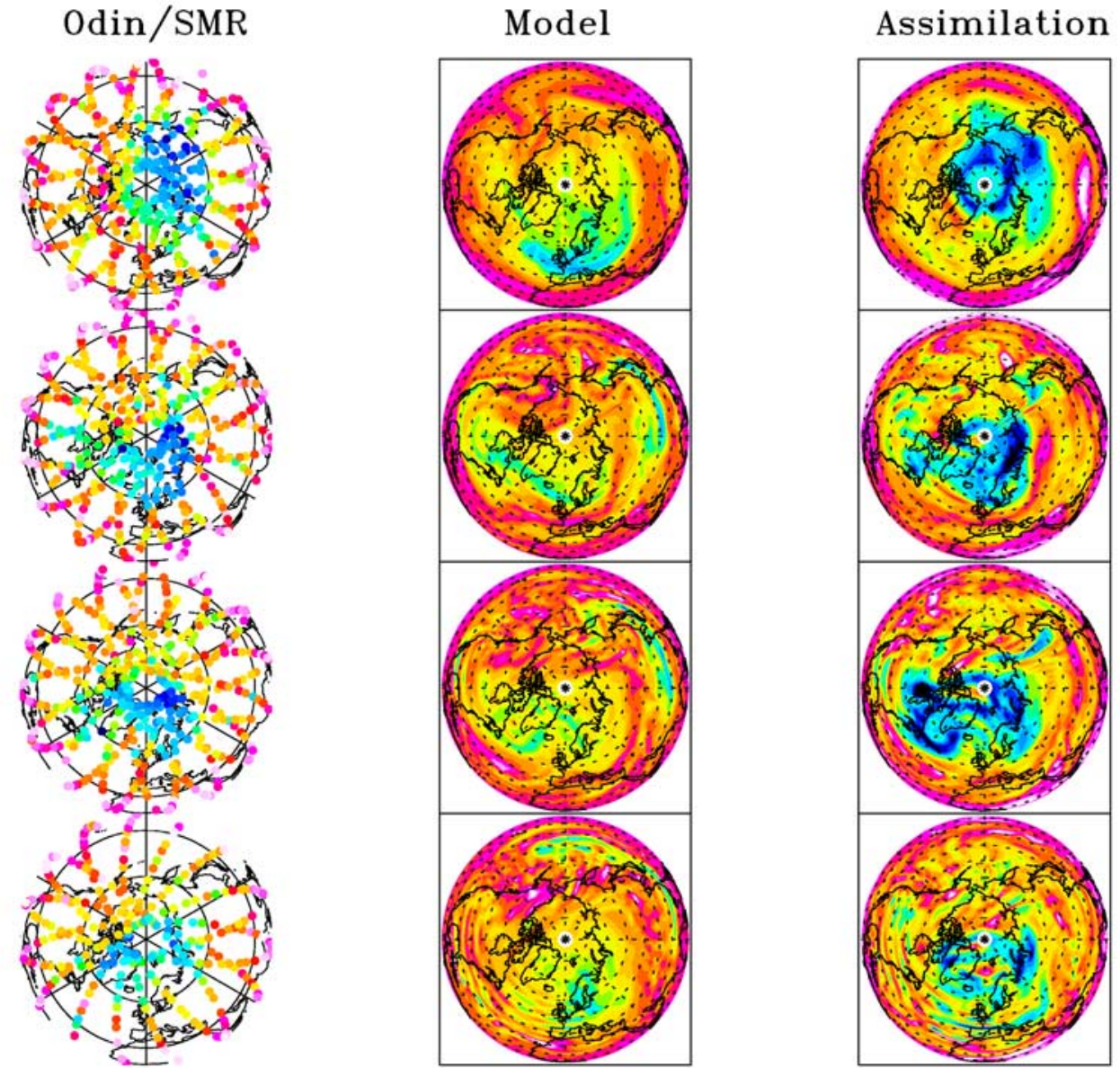

(a)

(b)

(c)

(d)

\section{$\begin{array}{llllllllll}25.0 & 53.5 & 82.1 & 110.6 & 139.2 & 167.7 & 196.3 & 224.8 & 253.4 & 281.9\end{array}$}

Figure 6. Same as Figure 5, but for nitrous oxide. The assimilated products are presented at $45.63 \mathrm{hPa}$. Measurements are interpolated on the same level.

are not localized, in contrast to what is given by the assimilated field where the corresponding minimum and maximum concentrations present a clear correlation with the measurements. However, the assimilated field shows finer structures. The ozone assimilated fields clearly show that the minimum of ozone at the beginning of the assimilation run is situated over Europe (Figure 5a), it moves after over the Atlantic Ocean (Figures 5b and 5c), and finally comes back over Europe (Figure 5d). In Figure 6 we present results obtained for nitrous oxide. The use of the 3D-CTM alone does not produce the minimal values of $\mathrm{N}_{2} \mathrm{O}$; however, in the end of the assimilation run (Figure 6d), the structure of the vortex begins to appear. We estimate that the date of the model initialization is not sufficient to produce the actual structure of the vortex for nitrous oxide and also for ozone: the model is initialized with a constant zonal mean distribution and thus many days of run are needed to produce the actual structures of the species fields. The model underestimates the nitrous oxide concentration in comparison with the assimilated fields especially in the minimum concentrations, however the localization of the minimum and the maximum concentrations are almost the same. The comparison of the nitrous oxide measurements with the assimilated field shows a very good agreement: the minimal and maximal concentrations are very localized. The northern polar vortex of nitrous oxide (minimum concentrations) 
evolution in the measurements and assimilated field is in a good agreement with the evolution of the ozone polar vortex (Figure 5).

\section{Conclusions}

[36] In this work we have presented an assimilation system capable to assimilate long-lived species in the stratosphere into a 3D-CTM. We have optimized the assimilation system to assimilate separately ozone and nitrous oxide measurements as measured by Odin/SMR.

[37] The parametrization of the forecast error covariance matrix makes the assimilation more flexible. The OMF diagnostic indicates that the correlation distances for Odin/SMR are optimal for values of $1500 \mathrm{~km}$ and $500 \mathrm{~km}$ in the meridional and zonal directions, respectively. This estimation seems to be independent on the assimilated molecule. However, the OMF and the $\chi^{2}$ diagnostics show that the model error depends on the assimilated molecule ( $12.5 \%$ for ozone and $18 \%$ for nitrous oxide). These results seem to be reasonable because, for the correlation distances, the geographical situations of measurements are the same for both molecules, but for the model error, the chemical characteristics are different from one molecule to the other.

[38] These assimilation runs are the first results obtained with the Odin/SMR measurements into a 3D-CTM. The objective of the present work was the optimization of the assimilation system with respect to Odin/SMR data. The analysis demonstrates its applicability to ozone and nitrous oxide. The comparison between ozone and nitrous oxide assimilated fields shows that the dynamical evolution of the ozone vortex is in very good agreement with the dynamical evolution of nitrous oxide vortex.

[39] At this first step, we are now able to perform more intensive scientific studies. We will focus on the Arctic and Antarctic ozone holes to apply the developed assimilation technique to investigate quantitatively the dynamical evolution of the vortices and chemical ozone loss.

[40] Acknowledgments. Odin is a Swedish-led satellite project funded jointly by Sweden, Canada, Finland, and France. This research was funded in France by contracts from the Centre National d'Etudes Spatiales (CNES) and from the Programme National de Chimie Atmosphérique (PNCA). In Sweden the work was supported by the Swedish National Space Board (SNSB). We would like to thank the ECMWF for providing the meteorological analyses.

\section{References}

Baron, P. (1999), Développement et validation du code MOLIERE: Chaîne de traitement des mesures micro-ondes du satellite Odin, Ph.D. thesis, Univ. Bordeaux 1, Bordeaux, France.

Becker, G., R. Muller, D. S. McKenna, M. Rex, K. S. Carslaw, and H. Oelhaf (2000), Ozone loss rates in the Arctic stratosphere in the winter 1994/1995: Model simulations underestimate results of the Match analysis, J. Geophys. Res., 105, 15,175-15,184.

Chipperfield, M. P. (1999), Multiannual simulations with a threedimensionnal CTM, J. Geophys. Res., 104, 1781-1805.

Chipperfield, M. P., B. V. Khattatov, and D. J. Lary (2002), Sequential assimilation of stratospheric chemical observations in a three-dimensional model, J. Geophys. Res., 107(D21), 4585, doi:10.1029/2002JD002110.
Elbern, H., and H. Schmidt (1999), A four-dimesional variational chemistry data assimilation scheme for Eulerian chemistry transport modeling, J. Geophys. Res., 104, 18,583-18,598.

Fierli, F., A. Hauchecorne, S. Bekki, B. Théodore, and O. F. d'Andon (2002), Data assimilation of stratospheric ozone using a high-resolution transport model, Geophys. Res. Lett., 29(10), 1381, doi:10.1029/ 2001GL014272.

Fisher, M., and D. J. Lary (1995), Lagrangian 4-dimensional variational data assimilation of chemical species, Q. J. R. Meteorol. Soc., 121(527A), $1681-1704$.

Hauchecorne, A., et al. (1999), Assimilation of GOMOS data of vertical ozone profiles in a 3-D chemistry-dynamics-transport model in the frame of MSDOL project, paper presented at European Symposium on Atmospheric Measurements From Space, Eur. Space Agency, Noordwijk, Netherlands.

Khattatov, B. V., J. C. Gille, L. V. Lyjak, G. Brasseur, V. L. Dvortsov, A. E. Roche, and J. W. Waters (1999), Assimilation of photochemically active species and a case analysis of UARS data, J. Geophys. Res., 104, $18,715-18,737$.

Khattatov, B. V., J. F. Lamarque, L. V. Lyjak, R. Menard, P. Levelt, X. Tie, G. Brasseur, and C. Gille (2000), Assimilation of satellite observations of long-lived chemical species in a global chemistry transport model, J. Geophys. Res., 105, 29,135-29,144.

Lautié, N. (2003), Traitement des mesures satellitaires sub-millimétriques effectuées par Odin/SMR; restitutions non-linéaire de la vapeur d'eau. II: Étude strato-mésosphérique de HCN au moyen de mesures micro-ondes, $\mathrm{Ph} . \mathrm{D}$. thesis, Univ. Paris VI, Paris, France.

Lefèvre, F., G. Brasseur, I. Folkins, A. K. Smith, and P. Simon (1994), The chemistry of the 1991-1992 stratospheric winter: Three-dimensional model simulations, J. Geophys. Res., 99, 8183-8195.

Levelt, P. F., B. V. Khattatov, J. C. Gille, G. P. Brasseur, X. X. Tie, and J. W. Waters (1998), Assimilation of MLS ozone measurements in the global three-dimensional chemistry transport model ROSE, Geophys. Res. Lett., $25,4493-4496$

Lorenc, A. C. (1986), Analysis methods for numerical weather prediction, Q. J. R. Meteorol. Soc., 112, 1177-1194.

Lukyanov, A. N., H. Nakane, and V. A. Yushkov (2003), Lagrangian estimations of ozone loss in the core and edge region of the Arctic polar vortex 1995/1996: Model results and observations, J. Atmos. Chem., 44, $191-210$.

Menard, R., and L. Chang (2000), Stratospheric assimilation of chemical observations using Kalman filter, part II: Chi-square validated results and analysis of variance and correlation dynamics, Mon. Weather Rev, 128, $2672-2686$

Murtagh, D., et al. (2002), An overview of the Odin atmospheric mission, Can. J. Phys., 80(4), 309-319.

Pierce, R. B., and T. D. A. Fairlie (1993), Chaotic advection in the stratosphere: Implications for the dispersal of chemically perturbed air from the polar vortex, J. Geophys. Res., 98, 15,589-15,595.

Rodgers, C. D. (2000), Inverse Methods for Atmospheric SoundingTheory and Practice, World Sci., River Edge, N. J.

Rose, K., and G. Brasseur (1989), A three-dimensional model of chemically active trace species in the middle atmosphere during disturbed winter conditions, J. Geophys. Res., 94, 16,387-16,403.

Savijärvi, H. (1995), Error growth in a large numerical forecast system, Mon. Weather Rev., 123, 212-221.

Urban, J., P. Baron, N. Lautié, K. Dassas, N. Schneider, P. Ricaud, and J. de La Noë (2004), Moliere (v5): A versatile forward and inversion model for the millimeter and sub-millimeter wavelength range, J. Quant. Spectrosc. Radiat. Transfer, 83(3-4), 529-554.

O. F. d'Andon, M. Guirlet, and B. Théodore, ACRI-ST, 06904 SophiaAntipolis, France.

J. De La Noë, E. Dupuy, L. El Amraoui, E. Le Flochmoën, P. Ricaud, and J. Urban, Observatoire Aquitain des Sciences de l'Univers, L3AB, 2, rue de l'Observatoire, 33270 Floirac, France. (amraoui@obs.u-bordeaux1.fr)

U. Frisk, Swedish Space Corporation, Solna strandvg 86, SE-171 04 Solna, Sweden.

A. Hauchecorne, Service d'Aéronomie du CNRS, 91371 Paris, France.

N. Lautié and D. Murtagh, Department of Radio and Space Science, Chalmers University of Technology, 41296 Göteborg, Sweden. 